\title{
AVALIAÇÃO DOS CURSOS DE GRADUAÇÃO A DISTÂNCIA NO CONTEXTO BRASILEIRO: A EXCELÊNCIA COMO GARANTIA DE PADRÃO DE QUALIDADE
}

\section{(QUALITY EVALUATION IN DISTANCE UNDERGRADUATE COURSES IN BRAZIL)}

\author{
Carla Netto \\ Instituto Educacional do Rio Grande do Sul, Brasil \\ Lucia Giraffa \\ Pontifícia Universidade Católica do Rio Grande do Sul, Brasil
}

\section{RESUMO}

Este artigo, resultado de uma tese de doutorado, investiga temas relacionados com a garantia de padrão de qualidade no processo de avaliação dos cursos de graduação na modalidade a distância, estabelecendo uma reflexão crítica entre o sistema brasileiro e o processo de acreditação internacional realizado nos Estados Unidos. O estudo consistiu numa análise qualitativa, descritiva, com estudo de caso, revisão de literatura e entrevistas com avaliadores e coordenadores de cursos de graduação na modalidade a distância (EAD) no Brasil. Os dados dos instrumentos foram analisados com base na metodologia de Análise Textual Discursiva (ATD). A pesquisa analisou o processo de avaliação dos cursos de graduação a distância nos EUA, identificando os indicadores de qualidade adotados por organismos internacionais de acreditação e, a partir da análise do processo de avaliação dos cursos de graduação a distância no Brasil, foi realizado um estudo sobre os resultados e impactos do sistema brasileiro, especialmente, dos indicadores utilizados e o grau de confiabilidade que possa surgir na relação com a avaliação da qualidade dos cursos na EAD. Como resultado dessa investigação indica-se a necessidade de estabelecer um padrão de qualidade no Brasil que tenha somente uma linha conceitual do que significa qualidade na modalidade a distância e a utilização de indicadores que possam expressar a excelência de uma graduação ofertada nessa modalidade de ensino. Essa excelência passa pela formação, experiência e conhecimento dos avaliadores e a definição de critérios e parâmetros precisos, claros e transparentes para medir a qualidade nos cursos de graduação na educação a distância. Para tanto, é necessário contar com um Banco de Avaliadores, não somente em condições de exercer sua função de maneira satisfatória, mas em número suficiente para colocar em prática o sistema de avaliação definido no Brasil.

Palavras-chave: qualidade em educação, qualidade em educação a distância, avaliação. 


\begin{abstract}
This paper, which is the result of a doctoral thesis, investigates aspects related to the quality assurance of distance undergraduate courses in Brazil. It provides a critical analysis of the Brazilian distance education system and compares it with the international accreditation process used in the USA. The study consists of a qualitative and descriptive analysis, several case studies, a literature review, and interviews with the evaluators and the coordinators of distance-run undergraduate courses (D.Ed.). The data from the instruments were then processed according to Discourse Textual Analysis (DTA). The evaluation process for undergraduate distance education courses in the USA was evaluated by identifying those quality indicators adopted by international accreditation agencies. Based on the analysis of the evaluation process of distance undergraduate courses in Brazil, a further study was carried out about the results and impacts of the Brazilian system, especially the indicators used and the level of confidence that existed when measuring the quality of distance-based undergraduate courses. As a result of this research, our researchers observed there was a real need to establish a quality assurance benchmark in Brazil along these conceptual lines, namely one that represents quality in D.Ed. and includes the usage of indicators that reflect the excellence of the degree course that are offered. This level of excellence is assessed on the basis of the training, experience, knowledge and skills of the evaluators, as well as on clear, precise and transparent criteria for measuring the quality-based distance degree courses. On the other hand, it is also necessary to be equipped with a Bank of Evaluators - not only for those who work in this field, but also for a group of experts that is large enough to implement the Brazilian evaluation system in distance education programs
\end{abstract}

Keywords: quality in education, quality in distance education, evaluation.

A EAD surgiu no Brasil em meados do século XIX com o ensino por correspondência e tinha seu principal objetivo voltado para o mercado de trabalho, oferecendo capacitação e formação profissional. Era usada para tornar a educação convencional acessível às pessoas residentes em áreas isoladas ou àqueles que não tinham condições de cursar o ensino regular no período apropriado.

Com a introdução do rádio na educação como meio de emissão rápida de informações, a EAD passou a ser desenvolvida também por meio de programas especiais transmitidos por emissoras de rádio em horários específicos. Em meados da década de setenta (1970), a televisão também passou a ser utilizada como um recurso na Educação a Distância. A introdução do som e da imagem em um mesmo veículo de comunicação despertou o interesse dos educadores pelo uso de materiais audiovisuais. (Faria, 2002).

Na década de noventa (1990), a EAD passou a contar com um novo recurso tecnológico: computadores ligados em rede. Isso aconteceu principalmente a partir de 1995, com o grande crescimento da internet, momento em que se configurou um novo espaço de interação, a partir do uso de ambientes virtuais de aprendizagem. (Maia e Mattar, 2007). 
Nessa década, a EAD começou a ter um novo desenho no contexto brasileiro através de algumas medidas adotadas pelo Ministério da Educação. Foi a partir da Lei ${ }^{\circ}$. 9.394/96, da LDB (Lei de Diretrizes e Bases da Educação), através do artigo 8o, que a Educação a Distância foi introduzida oficialmente no sistema nacional brasileiro como mais uma modalidade de ensino e de aprendizagem.

Assim, depois do marco regulamentário de 1996, houve uma expansão da educação superior a distância no Brasil, com os primeiros projetos de licenciatura para atender aos dispositivos legais de formação de professores. Essas experiências pioneiras possibilitaram o desenvolvimento de projetos pedagógicos distintos que configuraram uma variedade de modelos. (Torres et al., 2009).

Com a nova projeção dada para a EAD no Brasil, a qualidade dos cursos de graduação nessa modalidade de ensino passou a ser um dos tópicos de interesse do Ministério da Educação. Para auxiliar as instituições a promoverem cursos de EAD com a devida qualidade, a Secretaria de Educação a Distância (SEED) elaborou um documento chamado "Referenciais de Qualidade para Educação a Distância".

Esse documento, publicado em 2003 (atualizado em 2007), embora não tenha força de lei, constituiu-se em um elemento balizador para os atos legais do poder público relativos à $\mathrm{EAD}$, exercendo função indutora quanto à concepção, organização e funcionamento dos cursos de graduação no Brasil.

A expansão da oferta de matrículas no ensino superior na modalidade a distância nos anos seguintes foi muito significativa, mas essa extraordinária expansão não foi acompanhada do correspondente crescimento qualitativo, acarretando, assim, problemas de ordem administrativa e pedagógica.

Os órgãos responsáveis pelo acompanhamento dessas ofertas não encontravamse suficientemente preparados para a necessária supervisão. A lei do SINAES (Sistema Nacional de Avaliação da Educação Superior) foi exarada apenas em abril de 2004 e ainda encontrava-se em fase de consolidação.

O documento que definiu o que seria o SINAES e a legislação a ele vinculada deixaram claro que todos os cursos superiores teriam que, obrigatoriamente, receber uma visita in loco por uma comissão de especialistas para avaliação. As visitas deveriam acontecer de 3 em 3 anos, acompanhando o ciclo trienal do Exame Nacional de Desempenho de Estudantes (ENADE).

No entanto, conforme aponta Verhine (2009), essa proposta não era viável diante das condições reais existentes. Pela estimativa do INEP, apenas 12000 cursos (4000 a cada ano) receberiam a visita das comissões de avaliadores, de uma média 
de 28 mil cursos (presenciais e a distância, de instituições privadas e públicas). Assim, 16000 cursos ficariam sem a devida avaliação in loco.

O que pôde ser verificado na prática foi que "até o início de 2008 (quatro anos após a criação do SINAES), os únicos cursos visitados foram da área de Medicina Veterinária, com o propósito de pré-testar o instrumento que, no processo, se revelou deficiente" (Verhine, 2009, p. 640).

Diante desse contexto, com a expansão do número de matrículas em EAD e sem o acompanhamento adequado da qualidade dessas ofertas, uma variedade de problemas se manifestou, levando a questionamentos por parte de expressivos segmentos da sociedade até sobre a validade da oferta de graduação nessa modalidade de ensino.

Num tempo de supercomplexidade da educação superior, Morosini (2009) aponta que a necessidade da garantia de qualidade tornou-se uma das questões centrais no debate acerca da qualidade e da expansão da educação superior. No mundo globalizado, a qualidade se direciona para o conceito de garantia de qualidade. Muitos países vêm desenvolvendo e implantando sistemas de garantia de qualidade que, na maioria dos casos, tem como objetivo central assegurar e melhorar a qualidade (Morosini, 2008).

Os EUA, um dos objetos investigados nesta pesquisa, trabalha sob a ótica da acreditação como garantia da qualidade da educação superior. Esse método de garantia externa de qualidade é o mais utilizado no contexto internacional. É o resultado de um processo mediante o qual uma entidade pública (governamental) ou privada (agência de acreditação) avalia a qualidade de uma instituição, um programa ou curso de graduação, com o objetivo de reconhecer formalmente que cumpre determinados critérios ou padrões pré-determinados em sua 'totalidade' e conceder-lhe um selo de qualidade (Netto, Giraffa e Faria, 2010).

Dessa forma, um curso de graduação só recebe um selo de qualidade se atende a todos os critérios exigidos, ou seja, se atende a um padrão de qualidade estabelecido. No Brasil, a legislação do SINAES estabelece que as visitas das comissões de avaliação de um curso devem resultar na aplicação de conceitos ordenados em uma escala com 5 (cinco) níveis, a cada uma das dimensões e ao conjunto das dimensões avaliadas.

A obtenção de conceito final 3, 4 ou 5 atribuiria ao curso o status de satisfatório e estaria de acordo com a legislação. A obtenção de um resultado insatisfatório (conceito final 1 ou 2) levaria a elaboração de um protocolo de compromisso entre a instituição e o Ministério da Educação (MEC) para as melhorias identificadas como necessárias de serem efetuadas. 
Esse processo de aplicação de conceitos ordenados em escalas com níveis é um dos pontos questionados por pesquisadores das políticas de avaliação na educação superior brasileira com o foco na qualidade. Da forma como o processo de avaliação está organizado, a forma como o processo de avaliação da educação superior no Brasil está organizado leva a uma concepção de qualidade centrada na busca de conceitos mínimos na avaliação da qualidade dos cursos em detrimento de uma qualidade real dos serviços prestados e da criação de uma cultura de qualidade na oferta do ensino superior.

O atual sistema de avaliação dos cursos de graduação na modalidade a distância, mesmo com indicadores específicos para a $\mathrm{EAD}$, podem não assegurar um padrão de qualidade devido à forma como o processo está estruturado, definindo e aceitando níveis para a qualidade. Para tanto entende-se que a qualidade nos cursos de graduação a distância poderá ser alcançada através de processos adotados por sistemas de garantia de qualidade implementados internacionalmente, como a acreditação. Assim, há a necessidade de um processo claro, robusto e que dê conta da medida da qualidade dos cursos e avaliadores com preparo e conhecimento da modalidade e dos instrumentos que irão utilizar.

\section{METODOLOGIA}

A pesquisa constituiu-se numa análise qualitativa, descritiva, com estudo de caso, contando, para tal, com levantamento bibliográfico e pesquisa de campo, com apoio nos testemunhos de coordenadores de cursos de graduação na modalidade a distância e avaliadores de cursos de graduação, enriquecida com as contribuições buscadas na Análise Textual Discursiva (ATD) (Moraes e Galiazzi, 2007).

A abordagem qualitativa foi escolhida como forma de análise, pois se preocupa, nas Ciências Sociais, com um nível de realidade que não pode ser quantificado. Ou seja, ela trabalha com o universo de significados, motivos, aspirações, crenças, valores e atitudes, o que corresponde a um espaço mais profundo das relações, dos processos e dos fenômenos que não podem ser reduzidos à operacionalização de variáveis (Minayo, 1999, pp. 21-22).

O caso analisado nesta pesquisa é o 'processo de avaliação dos cursos de graduação em EAD'. Esse estudo de caso é do tipo analítico, porque se constitui, primeiramente, pelo caráter descritivo. Segundo Yin (1984) são os estudos de caso de cunho analítico os que podem proporcionar significativo avanço no conhecimento real do contexto. Assim, essa abordagem se integra aos interesses da pesquisa, porque permite voltar o olhar para o processo de avaliação dos cursos de graduação na modalidade a distância, no contexto brasileiro. 
Os sujeitos da pesquisa foram 8 avaliadores e 1 coordenador de curso de graduação a distância, considerando um universo de representatividade de todo o contexto brasileiro. A escolha dos sujeitos que fizeram parte da pesquisa procurou atender a duas especificidades: avaliadores de cursos de graduação a distância cadastrados no INEP e coordenadores de cursos de excelência, em instituições com IGC 5, o que explica o número reduzido de sujeitos da amostra.

Para a realização desta investigação utilizou-se como instrumentos de coleta de dados os seguintes instrumentos: análise documental e questionário. Os documentos que serviram de base para a pesquisa foram a legislação relativa ao processo de autorização e acreditação de agências e cursos nos EUA e o processo de avaliação utilizado pela agência DTEC. No Brasil, os documentos pesquisados foram a Constituição Federal, a LDB, a legislação relativa à avaliação da educação superior brasileira (SINAES) e os Referenciais de Qualidade para cursos de graduação a distância.

A análise das informações obtidas através da pesquisa de campo foi realizada de acordo com a abordagem de análise textual discursiva (ATD). A Análise Textual Discursiva (ATD) foi escolhida por corresponder a uma metodologia de análise dados e informações de natureza qualitativa com a finalidade de produzir novas compreensões sobre os fenômenos e discursos, possibilitando, ao mesmo tempo, uma participação na reconstrução dos discursos em que o pesquisador e os sujeitos da pesquisa se inserem.

\section{A EXCELÊNCIA COMO GARANTIA DE PADRÃO DE QUALIDADE EM EAD: O CAMINHO DESEJÁVEL}

No Brasil a qualidade dos cursos é avaliada através de um processo que atribui conceitos ordenados em escalas crescentes de níveis, que vão desde o conceito 1 até o conceito 5 (excelência). Esse sistema permite que os cursos que não possuem conceito final 5 (excelência), mas que atingem um conceito final 3 ou 4 permaneçam em atividade, pois são considerados como cursos com certo nível de qualidade (suficiente e muito bom, respectivamente). Ou seja, foi criado um sistema que não busca medir se a excelência ocorre, mas sim, se existe certo grau de qualidade na oferta do curso em questão.

Das 1190 ofertas de cursos superiores na modalidade a distância apenas 4 cursos possuem Conceito de Curso (CC) 5, ou seja, há no Brasil apenas 4 cursos com conceito final de excelência. Se somarmos os cursos que possuem Conceito Preliminar de Curso (CPC) 5, teremos apenas 11 cursos no cenário brasileiro que podem ser considerados excelentes, ou seja, menos de $1 \%$ do total de oferta. 
Se a pesquisa for delimitada em cursos de graduação em EAD com Conceito de Curso (CC) 5 em Instituições de Ensino Superior com Conceito Institucional (CI) também 5 (a excelência da excelência), a situação fica ainda mais crítica. Não há instituições de ensino superior de excelência ofertando cursos de graduação excelentes na modalidade a distância. O conceito encontrado na maioria dos cursos avaliados é o Conceito Preliminar de Curso (CPC) 3. Das 1190 ofertas de graduação na modalidade a distância no contexto brasileiro, a partir da análise feita no sistema eletrônico do MEC (e-MEC), 127 cursos possuem Conceito Preliminar de Curso (CPC) 3, ou seja, nas escalas de conceitos atribuídas pelo Ministério da Educação, a maioria dos cursos avaliados, e que estão sendo ofertados, não possuem excelência, mas são considerados satisfatórios.

Outro dado que preocupa diz respeito aos cursos não avaliados. Da oferta de 1190 cursos, temos atualmente $77 \%$ dos cursos ofertados sem conceito de curso e/ ou sem conceito preliminar de curso, ou seja, a maioria dos cursos que estão em atividade ainda não foi avaliada pelo Ministério da Educação.

A avaliação in loco é um dos pontos conflitantes acerca do processo de avaliação dos cursos. O documento que conceituou o SINAES e a legislação que o criou deixaram claro que todos os cursos superiores que compõem o sistema federal de educação teriam que obrigatoriamente receber uma visita por uma comissão de especialistas para avaliação dos cursos e que a periodicidade dessas visitas deveria acompanhar o ciclo trienal do ENADE.

No entanto, na opinião de Verhine (2010), visitar todos os cursos no sistema no período de três em três anos, da forma como o sistema está estruturado, nunca foi ou será factível. Assim, diante do impasse encontrado pelo MEC, de que até 2008 (quatro anos após a criação do SINAES) apenas a área de Medicina Veterinária tinha recebido visita in loco, algumas alternativas de solução foram pensadas. Dessa forma, optou-se por identificar, através de dados já existentes, os cursos em situação crítica e garantir para esses a visita in loco da comissão de avaliadores.

Dessa forma, o CPC (Conceito Preliminar de Curso) foi introduzido e passou a ser um mecanismo prático para assegurar a concretização da avaliação dos cursos. Esse índice de qualidade de cursos, construído a partir de dados existentes, atribui conceito (de 1 a 5) para todos os cursos no sistema, com exceção dos novos ou os que possuem informações insuficientes para o cálculo, que recebem um registro "Sem Conceito", S/C. Os que recebem conceito 1 ou 2 são avaliados, obrigatoriamente, in loco e os cursos com conceito 3,4 ou 5 podem solicitar uma visita avaliativa dentro de 30 dias ou o conceito preliminar é mantido como conceito final. Nesse novo cenário, a partir da implementação do CPC, Verhine (2010) aponta que em torno de $25 \%$ dos cursos precisariam ser visitados. 
Alguns autores (DIAS SOBRINHO, 2008; LIMANA, 2012) criticam o CPC pelas suas limitações nos tipos de dados utilizados dados e defendem a ideia de que a qualidade efetiva dos cursos seria mais bem avaliada a partir das visitas in loco. Dessa forma, deveria ser criado, no âmbito do INEP, as condições para executar a política de avaliação estabelecida inicialmente.

Apesar do CPC ter sido criado como um mecanismo prático para assegurar a concretização da avaliação dos cursos, dos 1190 cursos de graduação a distância ofertados no país, 926 não possuem ainda um índice de qualidade de curso construído a partir dos dados existentes e nem, tão pouco, receberam uma visita in loco.

Não se pode justificar essa situação tão somente ao fato de que os 926 cursos ofertados são cursos novos, pois há cursos autorizados em 2006 que não possuem índice de avaliação, como, por exemplo, alguns cursos das instituições selecionadas para a pesquisa, conforme dados apresentados na metodologia desta pesquisa.

A qualidade na Educação a Distância é um tema que necessita ocupar espaços significativos no debate atual. Propõe-se que se estabeleça um padrão de qualidade onde se tenha uma única linha conceitual do que significa qualidade na modalidade a distância e que se estabeleça um processo de avaliação efetivo, com indicadores que expressem a excelência dessa modalidade de ensino.

Embora o Ministério da Educação apresente um documento que aponte os caminhos que levam à qualidade na Educação a Distância, esse conceito não parece estar bem definido, pois alguns pontos não são especificados, como, por exemplo, a quantidade de alunos por professor e por tutor, o próprio perfil do tutor, entre outros. O que seria, então, representativo de qualidade na Educação a Distância?

Em países que utilizam sistemas de garantia de padrão de qualidade na avaliação dos cursos, os indicadores de qualidade são avaliados a partir de conceitos de sim ou não (atendem ou não atendem a determinado indicador). No caso do Brasil, a legislação do SINAES estabelece que as visitas das comissões de avaliação de um curso devem resultar na aplicação de conceitos ordenados em uma escala com 5 (cinco) níveis. Assim, a garantia de padrão de qualidade fica prejudicada com a utilização de níveis/escalas de 1 a 5 ao aceitar que os cursos que não atendem a todos os critérios de qualidade permaneçam funcionando.

O nível de qualidade que deve estar intrínseco na busca e na garantia de um padrão de qualidade nessa modalidade de ensino é a excelência da oferta dos cursos de graduação. Pela utilização de níveis/escalas de 1 a 5 na avaliação dos cursos de graduação a distância, pode-se inferir que, para a legislação do SINAES, a excelência é vista como o nível mais alto do conceito de qualidade. Dessa forma, aponta-se que a excelência dos processos é o que deve definir a busca e a garantia de padrão de 
qualidade na educação superior a distância no Brasil. A partir desse entendimento e do uso de apenas esse aspecto (escala) teremos maior clareza nos processos de avaliação, tanto por parte dos cursos avaliados como dos avaliadores, e a garantia da oferta de um curso com o mais alto padrão de qualidade para a sociedade brasileira.

O avaliador tem um papel de extrema relevância no processo de avaliação de qualquer curso e isso não foge a regra no caso da modalidade a distância. O perfil dos avaliadores, tanto em termos de formação e conhecimento do objeto avaliado, como experiência de atuação em processos avaliativos, são de extrema importância e impactam significativamente na avaliação dos cursos.

Pela legislação brasileira, a excelência está em um avaliador ter uma formação mínima em nível de doutorado. No entanto, pela brecha apresentada pela própria lei ( $\S 4^{\circ}$ do Art. 5) e pela realidade brasileira encontrada, muitos dos avaliadores que estão atuando possuem uma formação em nível de mestrado.

O relatório sobre os novos instrumentos de avaliação de cursos de graduação apresentado por Funghetto (2012), que apresenta a titulação dos avaliadores no ano de 2010, aponta que $27 \%$ dos avaliadores que atuaram nesse ano tinham a titulação de mestre. Esse cenário brasileiro fica evidenciado pelos próprios sujeitos da pesquisa, pois a metade dos avaliadores em EAD pesquisados possui uma formação em nível de mestrado.

A experiência em avaliação e conhecimento das especificidades da Educação a Distância foram uns dos aspectos evidenciados na fala de todos os sujeitos pesquisados como fundamentais para uma avaliação com qualidade. Não conhecer a modalidade do objeto que está sendo avaliado é um fator extremamente preocupante. Como aferir qualidade e garantir a excelência de um curso se o avaliador não entende a essência de um ensino mediado por tecnologias?

Assim, para que um profissional desempenhe a função de avaliar a qualidade de um curso de graduação a distância de forma eficaz e eficiente é imprescindível que tenha uma formação mínima em nível de doutorado (atendendo a legislação vigente), mas que além desse critério, apresente experiência em avaliação do ensino superior, um maior entendimento da.

A comissão de acreditação de um curso em EAD nos EUA é composta por, no mínimo, 5 avaliadores (presidente da comissão, examinador de padrões educacionais, examinador de padrões de negócios, um especialista para cada área temática e um observador).

No Brasil, na avaliação dos cursos a distância, a comissão é formada, em geral, por 2 avaliadores. Quando questionados sobre esse aspecto, a maioria dos entrevistados 
apontou que uma comissão de avaliação deve ser formada por, no mínimo, três avaliadores para que seja garantida a excelência na avaliação de todos os aspectos de um curso de graduação em EAD.

Diante do exposto, percebe-se a importância do avaliador na busca de excelência na avaliação dos cursos. $\mathrm{O}$ fato de termos profissionais avaliando o ensino superior sem um perfil determinado como de excelência para a função, põe em dúvida a garantia de qualidade e expõe a fragilidade do processo com a atual formação do Banco de Avaliadores no que diz respeito à modalidade a distância no Brasil.

As constantes mudanças na legislação no que se refere ao instrumento de avaliação dos cursos de graduação apontam uma oscilação na forma instrumental e crítica do que se entende por qualidade nessa modalidade de ensino e uma carência de aprofundamento constante nas especificidades da modalidade, evidenciada pelo uso de um instrumento único, tanto para o presencial como para a EAD.

No início de 2012, o Ministério da Educação disponibilizou um novo e único instrumento de avaliação de cursos (autorização, reconhecimento e renovação de reconhecimento) nos graus de tecnólogo, de licenciatura e de bacharelado para a modalidade presencial e a distância. A diferença estabelecida no instrumento entre o presencial e a EAD está nos indicadores específicos para a Educação a Distância nas três dimensões avaliadas (Organização Didático-pedagógica, Corpo Docente e Tutorial e Infraestrutura).

A Tutoria é um dos pontos que mais geram polêmica no que diz respeito à qualidade nessa modalidade de ensino. $\mathrm{O}$ atual indicador que avalia as atividades de tutoria considera como excelência quando essas atividades previstas/implantadas atendem a todas as demandas didático-pedagógicas da estrutura curricular. Nesse indicador, o entrevistado $\mathrm{C} 1$ apontou que em relação às atividades de tutoria o que também deveria ser avaliado é a capacidade de liderança e inteligência interpessoal do tutor.

Esse aspecto é de extrema importância se levarmos em consideração que é o tutor quem responde as dúvidas apresentadas pelos estudantes em relação ao conteúdo da disciplina oferecida, media a participação dos estudantes nas atividades síncronas e assíncronas, estimulando-os a cumprir as tarefas, atingir os objetivos propostos, avaliando a participação de cada um. Assim, a medição do tutor é de extrema importância, porque "é uma função docente, tanto na tutoria específica de uma disciplina, quanto na tutoria, em geral presencial, como um orientador de estudo" (Lemgruber, 2012, p. 8).

Conforme os Referenciais de Qualidade, um projeto de qualidade na modalidade a distância deve prever vias efetivas de comunicação e diálogo entre todos os 
envolvidos, criando condições para diminuir a sensação de isolamento, apontada como uma das causas de perda de qualidade no processo educacional e uma das principais responsáveis pela evasão nos cursos a distância.

A interatividade pressupõe contato em rede e caracteriza-se como uma teia de conhecimentos. Segundo Faria (2002, p. 100), ela “torna-se inevitável e indispensável para o ato comunicativo significativo entre as pessoas e entre as pessoas e a máquina; a comunicação intencional, por sua vez, é um componente do processo educativo".

Em relação à interação entre docentes, tutores e estudantes, os sujeitos da pesquisa consideraram que o que deve ser avaliado nesse indicador são aspectos relacionados com a infraestrutura. Assim, o ambiente virtual de aprendizagem deve ser avaliado, pois se configura num espaço no qual são favorecidas as interações entre os participantes de um grupo, sendo possível o desenvolvimento de ações compartilhadas.

É importante que os cursos de graduação em EAD tenham ambientes virtuais de aprendizagem e que esses sejam estruturados de tal forma que propiciem espaços de aprendizagem, onde o aluno não só receba a informação vinda do professor, mas que construa o conhecimento com ele e com seus pares através das ferramentas interativas disponibilizadas. Portanto, um curso na modalidade a distância com qualidade deve ser um espaço que privilegia a cooperação/colaboração e a construção de uma prática social com condições de favorecer o processo de ensino e de aprendizagem.

Quando questionados sobre quais outros indicadores específicos da EAD deveriam ser contemplados na dimensão Organização didático-pedagógica, os sujeitos da pesquisa destacaram a dosagem, distribuição e interconexão de conteúdos, devidamente sistematizados para todo o curso por intermédio de um quadro sinóptico de conteúdos a serem aprendidos ao longo do tempo e cada um a seu tempo. Mais do que em cursos presenciais, um aluno de curso EAD precisa entender de onde está saindo, onde está, para onde e por onde está avançando em seus estudos.

Na segunda dimensão - Corpo Docente e Tutorial, o instrumento apresenta seis indicadores específicos para a modalidade a distância: Experiência do (a) Coordenador (a) do curso em cursos a distância, Carga horária de Coordenação de curso, Relação entre o número de docentes e o número de estudantes, a Titulação e formação do corpo de tutores do curso, Experiência do corpo de tutores em educação a distância e a Relação de docentes e tutores-presenciais e a distância-por estudante.

Em relação ao indicador que avalia a experiência do coordenador do curso em EAD, os sujeitos pesquisados consideraram que o tempo de experiência de um coordenador não parece ser muito relevante para agregar qualidade a um curso. 
Dessa forma, para poder agregar qualidade seria preciso verificar a intensidade e, sobretudo, a natureza de tal experiência. Por exemplo, ter experiência em cursos na modalidade a distância baseado apenas em livro impresso, é quase irrelevante num projeto pedagógico que tenha outras mídias envolvidas. Assim, é preciso que o coordenador tenha um amplo conhecimento nos mais variados recursos que estão disponíveis para a EAD para que sua experiência seja critério agregador de qualidade a um projeto.

Em relação à carga horária prevista/implantada para a coordenação do curso, o tempo de dedicação que deve ter um coordenador em EAD depende das características do curso, em aspectos como: proporções e quantidade de alunos e professores envolvidos, distância e contexto dos polos, natureza prioritariamente teórica ou prática da área.

O certo, porém, é que um curso EAD ainda acarreta muito mais trabalho do que seu similar presencial. Assim, um total de, no mínimo, 25 horas semanais dedicados totalmente à coordenação, como vem sendo avaliado, é um adequado indicador de excelência.

Em relação ao indicador "relação entre o número de docentes e o número de estudantes", a média de 1 docente para 130 alunos (equivalente à 40h) não é representativo de excelência. Tudo depende da área do curso, de sua proposta e arquitetura pedagógicas, da natureza de seus materiais didáticos e da habilidade do professor para o emprego de tecnologias da informação e comunicação. No entanto, se levarmos em consideração que o professor é também responsável pela interação no ambiente virtual, essa média de 130 alunos é muito alta e não garantirá a devida interação do professor com o aluno.

Pelo modelo estipulado pelo MEC para um curso a distância, os tutores exercem a função de mediação no processo de ensino e aprendizagem. Nesse sentido, na opinião dos entrevistados, a titulação e a formação do corpo de tutores para garantir a qualidade do curso deve ser pós-graduados (e não pós-graduandos!), com dedicação à tutoria como opção profissional. Porém, é preciso registrar que o perfil humano é tão importante quanto à titulação e seus conhecimentos em tecnologias. $\mathrm{O}$ tutor deve ser uma pessoa comunicativa, estimuladora, confiável, tolerante às diferenças, perseverante e organizada.

No que diz respeito à experiência dos tutores do curso, tempo de experiência não é critério relevante para garantir qualidade ao processo; competência e dedicação, sim. Os tutores deveriam ser escolhidos mediante um processo seletivo que envolvesse capacitação com atuação efetiva na forma de estágio. As características mais importantes para um bom tutor só podem ser observadas em situações práticas, ao longo de um determinado tempo. 
Em relação ao indicador que avalia a proporção de tutores e estudantes, na opinião dos entrevistados, a média de estudantes por tutor representativa de excelência é aquela que permita que o tutor tenha seu olhar voltado para conteúdos, acompanhamento dos ambientes virtuais de aprendizagem e correção de trabalhos.

Na busca por critérios de qualidade nos cursos de graduação a distância, além da qualificação docente dos tutores, é preciso pensar nas condições de trabalho e na garantia de atendimento personalizado aos alunos, ou seja, é necessário refletir sobre a proporção de alunos para cada tutor. A legislação em EAD não estabelece a quantidade de alunos para cada tutor. Através dos referencias de qualidade, o MEC observa que a proporção adequada deve garantir boas possibilidades de acompanhamento e comunicação entre professor/aluno.

Em instituições que adotam a acreditação como sistema de garantia de qualidade, a relação alunos/professor (tutor) é, em média, de 20 alunos para cada professor, o que é um diferencial nesse critério de qualidade quando comparado ao Brasil, que tem uma média superior a 100 alunos.

Netto, Giraffa e Faria (2010, p. 106), em pesquisa realizada com coordenadores sobre critérios de qualidade para os cursos de graduação em EAD, apontam que para o aluno ter um atendimento individualizado e um acompanhamento personalizado da sua aprendizagem, a proporção adequada de alunos por tutor deve ser de, no máximo, 30/1. "Para que se utilize com cada aluno de 1 a 2 minutos, fica impraticável garantir qualidade de interação para mais de 30 alunos ativos”.

No novo instrumento de avaliação, o indicador que avalia a proporção dos tutores e estudantes engloba também os docentes. No entanto, na visão dos entrevistados, para medir a qualidade deveria ser separado docente de tutor, pois eles têm atribuições distintas; mas, evidentemente, isso também dependendo do modelo pedagógico adotado pelo curso e da área de conhecimento. Em princípio, um professor, enquanto autor do material didático e responsável por sua eficácia nos ambientes virtuais do curso, pode atender um número infinito de alunos. Por outro lado, enquanto ministrante de uma disciplina, deve se limitar a um número reduzido.

Na terceira dimensão-Infraestrutura, o instrumento apresenta apenas um indicador específico para a modalidade a distância: Sistema de controle de produção e distribuição de material didático (logística). Além desse elemento específico da modalidade a distância, outro aspecto que deveria ser contemplado na avaliação da qualidade de um curso em EAD diz respeito aos recursos tecnológicos, como os laboratórios de informática equipados com webcam, caixas de som, filmadora e projetor multimídia, telefone liberado, internet rápida e com acesso liberado, devidamente atendidos por um técnico de informática. 
Assim, um projeto de qualidade em EAD precisa oferecer laboratório de informática de livre acesso, que apresente estrutura compatível com o número de estudantes atendidos e possua equipamentos modernos e atualizados. Esse espaço físico é uma forma de garantir que o aluno tenha acesso às salas de aulas virtuais (quando o modelo do curso utilizar espaço virtual) e à biblioteca digital.

Diante da realidade pesquisada na modalidade a distância, percebe-se que ainda precisamos caminhar em busca da qualidade que garanta excelência dos processos mediados por tecnologias. Essa excelência passa pela formação, experiência, conhecimento e capacitação dos avaliadores. Assim como é de extrema importância também se pensar no significado de qualidade para essa modalidade e definir critérios e parâmetros precisos, claros e transparentes para medi-la. Além disso, se faz necessário ter um Banco de Avaliadores, não só aptos a exercerem sua função com a devida qualidade, mas em um número que seja suficiente colocar em prática um sistema de avaliação criado.

\section{CENÁRIOS A (RE)DESENHAR A AVALIAÇÃo DA QUALIDADE DA GRADUAÇÃO A DISTÂNCIA}

Observa-se na comunidade internacional um movimento de internacionalização e busca de standards na educação superior em função da necessidade de integração gerada pela globalização da economia mundial. Dessa forma, um sistema de controle de garantia de qualidade como a acreditação vem ganhando cada vez mais espaço e sendo definido como um mecanismo adequado frente à diversidade de instituições de ensino superior, à multiplicidade de novas ofertas de cursos e à internacionalização da educação, porque assegura o controle (padrões) de qualidade ao aplicar procedimentos adequados, justos e imparciais, auxiliando na identificação de problemas e permitindo que medidas corretivas sejam imediatamente adotadas para a melhoria da qualidade.

No entanto, antes mesmo de caminhos serem apontados, é imprescindível refletir acerca da importância de se ter um processo de avaliação definido não só no papel, mas que seja colocado em prática de forma efetiva. Não adianta a discussão acerca de aspectos como avaliadores e indicadores de cursos utilizados por uma comissão, se mais da metade dos cursos serão avaliados a partir de outros critérios que não atendem a especificidade da modalidade, devido à falta de infraestrutura para a implementação do que era definido por lei.

Assim, é importante destacar que o uso de mecanismos como o Conceito Preliminar de Curso (CPC) não deveria ser aplicado, da forma como está estruturado, aos cursos de graduação na modalidade a distância, pois os componentes que o constituem não avaliam as especificidades da modalidade EAD. 
Dessa forma, os dois cursos de graduação que a pesquisa identificou como excelentes por apresentarem Conceito Preliminar de Curso 5, em instituições de ensino superior com Conceito Institucional 5 , foram avaliados como cursos excelentes a partir de indicadores que podem não medir satisfatoriamente as especificidades da Educação a Distância.

Essa questão traz à discussão o conceito que se tem de qualidade na modalidade a distância. Não é possível avaliar a qualidade da EAD a partir de critérios do presencial, pois há especificidades inerentes a essa modalidade de ensino. Uma modalidade que se caracteriza por ter na maior parte do processo o professor distante fisicamente do aluno, deve ser avaliada no seu contexto, considerando o impacto que essa forma de aprendizagem tem no processo de construção do conhecimento por parte do aluno.

É importante, ainda, destacar que esta pesquisa não buscou traçar um modelo de sistema de avaliação para os cursos de graduação a distância no Brasil. O objetivo da pesquisa foi identificar e delinear algumas alterações que devem ser contempladas no processo de avaliação dos cursos, a fim de que os resultados possam garantir um padrão internacionalmente aceito para os cursos na modalidade a distância.

Com a finalidade de [re]desenhar cenários e caminhos para a garantia de um padrão de qualidade na Educação a Distância, tendo a excelência como ponto de partida e de chegada, defende-se que é preciso repensar os requisitos integrantes do processo de avaliação dos cursos de graduação na modalidade a distância.

Uma especificidade da EAD que merece destaque diz respeito aos recursos humanos. O papel do professor conteudista e do tutor a distância apresentam diferenças significativas. Para um profissional que está em constante interação com o aluno, como no caso do tutor, que media a construção do conhecimento, que avalia atividades e corrige provas, é imprescindível que tenha, no mínimo, especialização e uma formação básica na área que atua, além de conhecimento das especificidades da modalidade de ensino.

É de extrema importância e urgência delimitar a quantidade de alunos por tutor. A média de mais de 100 alunos para um profissional que exerce uma função primordial que é a mediação da construção do conhecimento não pode ter uma quantidade muito grande de alunos, como vem sendo feito.

Para que seja garantida a excelência no processo de mediação, é necessário que um tutor tenha uma média de 30 alunos, conforme apontado por pesquisa realizada por Netto, Giraffa, Faria (2010) e pelos indicadores de qualidade adotados por outros países que utilizam mecanismos de garantia de padrão de qualidade. 
É preciso que o sistema de avaliação seja pensado levando em consideração as especificidades da modalidade a distância e que a excelência na EAD seja medida através de parâmetros claros e transparentes. Essa transparência não deve ser apenas direcionada para a instituição de ensino superior, mas para a sociedade como um todo.

No processo de acreditação dos EUA, os indicadores e os nomes dos avaliadores, por exemplo, são divulgados para toda a sociedade. Da mesma forma, quando uma instituição solicita acreditação, seu nome é divulgado para que o público em geral envie qualquer comentário que considere ser relevante a respeito da instituição e do curso dentro de um prazo determinado. Essa medida adotada auxilia na garantia de qualidade do que está sendo avaliado.

O avaliador exerce uma função de extrema importância num sistema de avaliação. Assim, na busca de excelência na avaliação dos cursos, é preciso que esses profissionais tenham qualificação adequada para exercerem essa função. Essa qualificação passa pela formação, em nível de doutorado, conhecimento do objeto avaliado e das especificidades da Educação a Distância e experiência em avaliação.

Entende-se que a partir de um novo olhar acerca do que significa padrão de qualidade, o uso de escalas e níveis não terá mais espaço. A relevância deste trabalho está em promover a reflexão acerca do que significa qualidade na modalidade a distância e que a excelência nessa modalidade de ensino requer um processo de avaliação efetivo, com indicadores que expressem a garantia de qualidade da Educação a Distância.

É possível termos qualidade nos cursos de graduação a distância, desde que se desenvolva uma política de avaliação que inclua o uso de indicadores específicos para essa modalidade de ensino e a formação/identificação de um conjunto de avaliadores capacitados (e em número suficiente em face de demanda crescente). Talvez o primeiro passo para essa mudança seja aceitar que qualidade não pode ser medida de forma fragmentada, quando os processos de acreditação apontam para soluções mais objetivas na avaliação dos critérios escolhidos. 


\section{REFERÊNCIAS BIBLIOGRÁFICAS}

Dias Sobrinho, J. (2000). Avaliação da Educação Superior. Rio de Janeiro: Vozes.

Faria, E. (2002). Interatividade e Mediação Pedagógica na Educação a Distância. PUCRS: Porto Alegre.

Funghetto, S. (2012). Novos Instrumentos de Avaliação de Cursos de Graduação. Recuperado de http://www.abmes. org.br/abmes/public/arquivos/ documentos/2011-07-04-Suzana-INEP. pdf.

Limana, A. (2012). Desfazendo mitos: o que estão fazendo com o SINAES? Recuperado de http://www.scielo.br/ pdf/aval/v13n3/18.pdf
Maia, C., e Mattar, J. (2007). ABC da EAD: a educação a distância hoje. São Paulo: Pearson.

Moraes, R., e Galiazzi, M. (s/f). Análise Textual Discursiva. Ijuí: Unijuí.

Netto, C., Giraffa, M., e Faria, E. (s/f). Graduações a Distância e o Desafio da Qualidade. Porto Alegre: EDIPUCRS.

Torres, P., Vianney, J., e Roesler, J. (2009). Educación Superior a Distancia em Brasil. In La Educación Superior a Distancia em America Latina y El Caribe: realidades y tendências. Palhoça: Ed. Unisul.

Verhine, R., (s/f). O Novo Alfabeto do SINAES: reflexões sobre IDD, CPC e IGC. Belo Horizonte: ENDIPE.

\section{PERFIL ACADÉMICO Y PROFESIONAL DE LAS AUTORAS}

Carla Netto. Pós-doutorado em andamento na Universidad Nacional de Educación a Distancia-UNED. Doutora em Educação, com Doutorado sanduíche na The University of Texas at Austin, Mestre em Educação em Ciências e Matemática, Especialista em Educação a Distância e Pedagoga em Multimeios e Informática Educativa, pela Pontifícia Universidade Católica do Rio Grande do Sul-PUCRS. Possui experiência na área da Educação, com ênfase em Educação a Distância, atuando principalmente nos seguintes temas: Educação a Distância, Informática na Educação, Ambientes Virtuais de Aprendizagem, Formação Docente em EAD, Qualidade do Ensino Superior na Modalidade a Distância e Acreditação da Educação Superior.

E-mail: netto.carla@gmail.com

DIRECCIÓN DE LA AUTORA

IERGS-Instituto Educacional Rio Grande do Sul

Vigário José Inácio, 153-Centro-Porto Alegre-RS-Brasil

Lucia Giraffa. Pós-Doutorado na Universidade do Texas (Austin) no College of Education, Bolsista CAPES, Doutorado em Ciências da Computação pela Universidade Federal do Rio Grande do Sul, Mestrado em Educação pela Pontifícia Universidade Católica do Rio Grande do Sul, Especialização em Análise de Sistemas pela Pontifícia 
Universidade Católica do Rio Grande do Sul, gr.aduação em Licenciatura Curta Em Ciências pela Universidade Federal do Rio Grande do Sul.

E-mail: giraffa@pucrs.br

DIRECCIÓN DE LA AUTORA

PUCRS - Pontifícia Universidade

Católica do Rio Grande do Sul

Av. Ipiranga, 6681-Partenon-Porto

Alegre | RS | Brasil

Fechas de recepción del artículo: 30/04/14

Fecha de aceptación del artículo: 26/07/14

\section{Como citar este artículo:}

Netto, C., y Giraffa, L. (2015). Evaluación de la calidad de los cursos de pregrado distancia en contexto de Brasil. RIED. Revista Iberoamericana de educación a Distancia, volumen 18, $\mathrm{n}^{\mathrm{O}}$ 1, pp. 91-108. 